\title{
SUBSÍDIOS PARA O ESTUDO DA INSTALAÇÃO DA PECUÁRIA EM MINAS GERAIS.
}

\author{
ONEYR BARANDA \\ Da Faculdade de Filosofia, Ciências e Letras da Univer- \\ sidade Federal de Minas Gerais.
}

A instalação da pecuária em Minas Gerais parece-nos um tema que não foi ainda devidamente elucidado. Sendo a atividade pastoril uma das mais importantes da história econômica do território mineiro, seu estudo pode esclarecer muitos dos pontos obscuros das diversas crises político-sócio-econômicas que surgiram no início do povoamento. Antes da descoberta do ouro, os rebanhos dos criadores paulistas já se espalhavam pelas margens do São Francisco e pelos campos circunvizinhos de Ibituruna e Baependí, permitindo o aparecimento de condições necessárias à sobrevivência dos primeiros mineradores. Coube aos criadores a tarefa de assegurar a alimentação do excedente demográfico, preocupado exclusivamente em minerar. Durante tôda a primeira fase da ocupação das minas, a vida econômica era dirigida por êsses fazendeiros do São Francisco, que montaram uma verdadeira rêde de produção e distribuição de carne aos nascentes arraiais. Era do campo que vinham as diretrizes das transações, o comércio sendo exercido diretamente entre produtores e consumidores. $\mathrm{O}$ ouro produzido mudava ràpidamente de dono, enriquecendo os vaqueiros em detrimento dos mineiros, explorados pelos preços exorbitantes. Com o acúmulo de riquezas, os criadores multiplicavam seus rebanhos e, donos de vastos domínios, controlavam todo o abastecimento, impondo suas condições à população necessitada. A crescente expansão dêsse poderio deu-lhes o prestígio político, fato que semeou ódios e consolidou ressentimentos entre aquêles que não tinham um rendimento tão estável $e$ independente dos caprichos da sorte. A guerra dos emboabas, inevitável choque de duas mentalidades opostas que pugnavam pela dominação econômica, além de desarticular o monopólio paulista, abalou a hegemonia da zona rural, com a ascensão dos comerciantes urbanos. Recolhidos às suas propriedades, os criadores passaram a ser dominados pelos 
intermediários que, fixados em vilas afastadas dos centros de produção, conheciam melhor as oscilações do mercado e podiam assim obter maiores lucros e facilidades junto ao govêrno. A classe dos marchantes substituiu a dos pecuaristas: o comércio de carne foi ampliado além das fronteiras, envolvendo interêsses do Rio de Janeiro, Bahia e São Paulo, numa vasta circulação interna de riquezas. Foi essa substituição dos criadores pelos marchantes que tornou possível a configuração nitidamente urbana do povoamento de Minas Gerais .

A instalação efetiva da pecuária no sertão mineiro foi iniciada pelos habitantes de São Paulo, que introduziram o gado tanto ao norte quanto ao sul da futura capitania. Ao norte, os primeiros currais foram fundados por paulistas, ao findar a "guerra dos bárbaros". Durante tôda a primeira metade do século XVII, o sertão do São Francisco permanecera impenetrável à civilização européia. Reduto de índios ferozes, de negros quilombolas e de criminosos brancos, sua travessia era uma aventura perigosa. As necessidades de expansão econômica impeliam à ocupação do vale, mas os esforços só tiveram início após o término da guerra contra os holandeses. Em 1650 , foram concedidas as primeiras sesmarias, e os fazendeiros encarregaram-se da direção dos trabalhos de expulsar os gentios. Os Garcia d'Ávila combateram os cariris, dominando a margem esquerda do rio e ampliando suas pastagens até o Piauí. Coube a Antônio Guedes de Brito a pacificação da outra margem.

O imenso latifúndio de Antônio Guedes de Brito nascera de uma modesta sesmaria de 6 léguas, em 1655. O lucro com a exportação de couro e com a venda de carne aos engenhos, fêz-lhe ampliar suas terras e, em 1667, já era senhor de 160 léguas de sesmarias contínuas, rumo às nascentes do rio das Velhas. Com a concessão, foram-lhe outorgados os títulos de Mestre de Campo e Regente do Rio São Francisco, com a obrigação de garantir aos colonos o trânsito, exterminando o perigo indígena. Para realizar essa gigantesca operação de guerra, lembrou-se da fama de grandes sertanistas dos moradores de Piratininga e, em fevereiro de 1677, convidou-os a passar ao rio São Francisco, região que até então lhes era proibida, a fim de lutar contra os índios que tinham

$$
\text { "degolado e desbaratado já tão várias bandeiras de paulistas" (1). }
$$

Além dos apelos à honra e ao sentimento de vingança, mostrouthes as amplas possibilidades de exploração econômica da zona a ser

(1) - Carta de Antônio Guedes de Brito e outros, 20/II/1677,Documentos Históricos, vol. XI, Rio de Janeiro, Biblioteca Nacional, 1929, pág. 71. 
pacificada, ideal para a instalação de fazendas. Os bandeirantes, ante as pespectivas de vultosos lucros com a escravização dos vencidos, concordaram em participar das lutas e extirparam os últimos focos de resistência. Antônio Guedes de Brito havia concebido um plano de

\footnotetext{
"um vasto senhorio repartido entre foreiros que por interêsse próprio defendessem o território repartido" (2).
}

Dividiu sua propriedade em sesmarias de 1 légua, para distribuição aos participantes da guerra, com a única condição de pagamento de fôro de 10.000 réis anuais. Pensava, ao adotar essa organização quase feudal, não só em assegurar a conquista do rio São Francisco, fixando no local os guerreiros sedentarizados pelas atividades agro-pastoris, como também em aumentar seus rendimentos, pelo contrôle do comércio da produção de seus foreiros. Terminadas as hostilidades, muitos dos combatentes preferiram permanecer a voltar às precárias condições de vida do planalto, e aceitaram os oferecimentos do potentado baiano. A abundância de água, de caça e pesca, a vastidão das pastagens naturais e a existência de sal-gema nos barrancos ribeirinhos, fizeram prosperar os incipientes criadores e logo

\footnotetext{
"muitos dêles, transportando por êle suas mulheres e famílias, mudaram totalmente os seus domicílios de São Paulo para as beiras do dito rio de São Francisco, nos quais hoje se acham mais de cem casais, todos paulistas, e alguns dêles com cabedais muito grossos",
}

informa um anônimo do início do século XVIII (3).

Essas primeiras fazendas dependiam exclusivamente da praça da Bahia, para onde eram enviadas as boiadas, que eram adquiridas pe los preços impostos pelos marchantes baianos. Os rendimentos por cabeça de gado não eram satisfatórios, porque as grandes distâncias desfalcavam os rebanhos e provocavam a queda sensível do pêso de cada rês. Os novos criadores ampliavam suas pastagens, procurando suprir com o volume de vendas o pequeno preço unitário alcançado. A zona de criação, desprovida de barreiras artificiais ou naturais, propiciava essa ampliação, e as fazendas cresciam, espalhando-se pelas margens dos afluentes. Enquanto a pecuária sofria essa expansão contínua ao norte de Minas Gerais, ao sul as dificuldades econômicas limitavam as suas possibilidades lucrativas.

(2). - Dlogo de Vasconcelos, História Média de Minas Gerais, Belo Horizonte, Imprensa Oficial, 1918, pág. 27.

(3). - "Tnformaçóes sôbre as minas do Brasil", Anais da Biblioteca Nacional, vol. LVII, Rio de Janeiro, Minístério da Educação, 1935, pág. 112. 
Ao sul, os primeiros rebanhos tinham sido introduzidos nos arredores de Baependí e Ibituruna, para assegurar a alimentação das expedições que percorriam esporàdicamente o território. Era um escasso número de rêses mirradas, suficiente porém para as pequenas necessidades de subsistência dos esparsos moradores. As notícias dos sucessos de Fernão Dias Pais impeliram a Corôa a enviar para os descobertos o especialista em mineração, D. Rodrigo de Castelo Branco, que além de um grande contingente militar, conduziu para a região cabeças de gado bovino e cavalar. A crise com Borba Gato, resultante de choques de autoridade entre o funcionário e o caudilho, culminando com a morte do fidalgo, dispersou a expedição. Os soldados amedrontados apoderaram-se dos animais e embrenharam-se pelos campos de Sete Lagoas, onde se fixaram com fazendas de criação (4). Essas fazendas progrediram lentamente, devido à inexistência de um mercado consumidor: os preços alcançados em São Paulo não compensavam o trabalho da penosa travéssia, sem currais intermediários para assegurar a alimentação dos rebanhos. Apesar da falta de incentivo, os campos foram ocupados e quando começou o surto de mineração, a pecuária já era uma atividade sòlidamente instalada no sertão mineiro.

Em 1698, os ribeiros auríferos foram invadidos por hordas de faiscadores e bateadores. A corrida para as minas esvaziara as regiões agrícolas litorâneas e os portos começaram a receber grandes levas de reinóis que procuravam riquezas no interior da colônia. $O$ excesso repentino de população desorganizou o abastecimento e a carne era disputada a qualquer preço nos arraiais. Os criadores paulistas do São Francisco viram nesse nôvo mercado uma possibilidade de se libertarem da opressão dos grandes comerciantes baianos. A princípio tímida, mas regularmente, iam desviando seus rebanhos da praça da Bahia para os centros urbanos do vale do rio das Velhas, e implantaram um tráfico intenso de ouro e gado. Os currais multiplicaram-se, até a barra daquêle rio, e sucediam-se, sem interrupção, de duas em duas léguas (5). Como não havia ainda preparação para um comércio em larga escala, organizavam-se apenas pequenas boiadas de 30,50 bois, que mal passavam dos primeiros arraiais, onde eram totalmente compradas. As populações mais afastadas não conseguiam adquirir o gado necessário a seus açougues com os criadores do sul, incapazes de aumentar repentinamente sua produção. $\mathrm{E}$ veio a grande fome, que causou o abandôno das lavras: os mineradores voltaram para suas vilas ou fixaram-se em terraços férteis, aguar-

(4). - Dlogo de Vasconcelos, História Antiga de Minas Gerais, Belo Horizonte, Imprensa Oficlal, 1904, pág. 55.

(5). - "Informaçóes sôbre as minas do Brasll", ibidem, pág. 108. 
dando as colheitas. Em carta de 20 de maio de 1698, o governador Artur de Sá e Menezes depõe:

"Chegou a necessidade a tal extremo que se aproveitaram dos mais imundos animais, e faltando-lhes êstes para poderem alimentar a vida, largaram as minas e fugiram para os matos com os seus escravos a sustentarem-se com as frutas agrestes que neles achavam" (6).

A pecuária também se ressentiu da crise; as boiadas não encontravam compradores nos lugarejos desertos.

As grandes levas de gado adquirido na Bahia e Pernambuco pelos paulistas e as primeiras colheitas trouxeram de volta os mineradores. As catas e as grupiaras foram reabertas e a normalidade foi restabelecida. Para evitar a repetição do colapso, o governador tentou promover o aumento da produção de gêneros de primeira necessidade e facilitar o acesso às minas através da abertura de novos caminhos (7). Enquanto essas medidas oficiais procuravam ampliar a criação ao sul, ao norte a iniciativa privada tentava equipar-se para as lucrativas perspectivas do comércio. A prosperidade dos criadores paulistas despertou a cobiça dos baianos que começaram a subir o São Francisco, à procura de pastagens onde, escapando ao contrôle dos latifundiários, pudessem introduzir-se no nôvo mercado. Instalaram-se no vale do Gorutuba, com os grandes currais de Montes Claros e Olhos D'Água, mas não escaparam ao predomínio paulista que monopolizava tôda a criação no território mineiro. O comércio de gado florescia e o São Francisco transformou-se numa grande via comercial, com movimentação intensa de vaqueiros e boiadas.

Cabia aos paulistas o domínio de tôda a vida econômica das minas. Na pecuária, estavam em suas mãos, além da criação e distribuição dos rebanhos, a cobrança dos direitos de passagem e dos dízimos. Eram donos também dos maiores currais de estada obrigatória, como em Contagem e Curral del Rei, de onde o gado era redistribuido aos compradores mais distantes. Esses antigos guerreiros transformados em potentados rurais desafiavam o próprio fisco e arvoraram-se em senhores do vale, sem mais se lembrarem do pagamento de antigos compromissos de fôro aos descendentes de Antônio Guedes de Brito. $O$ nome de um paulista era um salvo-conduto para o viajante daquelas paragens despoliciadas. Verdadeiros caudilhos, impunham sua

(6). - Carta de 20 de maío de 1698, Manuscrito do Arquivo Nacional. Coleção Governadores, volume VI, pág. 117.

(7). - Mafalda P. Zamella, o abastecimento da Capitania de Minas Gerais no Século XVIII, São Paulo, Unlversidade de São Paulo, 1951, pág. 39. 
vontade e sua lei, manobrando uma vasta rêde de boiadeiros e prepostos, auferindo lucros extraordinários como intermediários das grandes negociações. Eliminaram a classe dos marchantes, comerciando diretamente com os centros consumidores. Acumulavam riquezas, ignorando o pagamento de direitos à Corôa, já que era difícil uma fiscalização naqueles remotos rincões.

O ouro saíadas minas sem ser quintado, e aos fiscais apresentava-se uma relação fictícia dos rendimentos. Inncapaz de impedir essa sonegação contínua, impossibilitada de organizar um policiamento que diminuisse o poderio paulista, pressionada pelos comerciantes litorâneos, a metrópole resolveu adotar a solução mais fácil para o problema: o fechamento sumário do caminho para a Bahia. A carta régia de 7 de fevereiro de 1701 declarava que

\footnotetext{
"por convir a meu serviço fui servido resolver que as capitanias de Bahia e Pernambuco se não comuniquem pelos sertões com as minas de São Paulo, nem das ditas minas se possam ir buscar gados ou outros mantimentos às sobreditas capitanias, nem também delas trazerem-se às minas" (8).
}

O governador, lançado o bando para a execução das ordens, instituiu a fiscalização severa nos registros de passagem e incentivou a delação com prêmios. A infinidade de trilhas no sertão e a não existência de um corpo policial organizado, permitiram a continuação dos descaminhos, apenas com a diminuição de intensidade do movimento. Como tôda a administração da zona aurífera era exercida pelos paulistas e sendo êles os maiores interessados no rendoso comércio, as resoluções foram pràticamente ignoradas. Sòmente os criadores baianos amedrontaram-se com as ameaças de confiscação e multa e colocaram seus rebanhos sob seu contrôle, submetendo-se mesmo a simulacros de roubo para garantir a continuidade do tráfico: os paulistas fingiam assaltos aos comboios, ajustavam com os proprietários o valor das rêses e continuavam tranquiilamente a abastecer seus currais. Para impedir diligências inesperadas de alguma autoridade estranha e mais zelosa, usavam o expediente de registrar a boiada em nome de um compatriota que oficialmente estaria enviando-a a um curral próximo (9). Assim, de curral em curral, de criador a criador, o gado chegava ao mercado, com lucros aumentados pela especulação. O contrabando, se não era aceito pelas autoridades, era tolerado, pois havia necessidade de assegurar o abastecimento da população. As regiões sulinas não conseguiam fornecer sòzinha sa car-

\footnotetext{
(8). - Carta régia de 7 de fevereiro de 1701, Documentos Interessantes, volume LI, Arquivo do Estado de São Paulo, 1930, pág. 19.

(9). - "Informaçóes sôbre as minas do Brasil", ibidem, pág. 117.
} 
ne necessária. São Paulo, que se despovoara para povoar o interior, esvaziara seus mercados e seus comerciantes viram-se obrigados a adquirir animais em Curitiba e Paranaguá para o sustento dos próprios habitantes. Rio de Janeiro, apesar de possuir uma razoável número de currais, era isolado das minas pelos longos dias de jornada, através de regiões difíceis e desertas. Era urgente instalar a pecuária em território mineiro, e facilitar as comunicações.

Aos 18 de março de 1702, o govêrno decretou a repartição em sesmarias das terras localizadas nos campos dos Cataguases, para o estabelecimento de fazendas de criar, com um prazo de três anos para a ocupação efetiva dos lotes. Essas sesmarias deveriam ser o mais próximas possível das minas, conservando apenas terrenos baldios para o sustento do gado,

"sem que lhe seja necessário que o vão buscar em maior distância" (10) .

Muitos solicitaram lotes para se dedicarem a novas atividades, principalmente reinóis que procuravam um compensador meio de vi$\mathrm{da}$, desiludidos com a mineração. O próprio Borba Gato obteve uma concessão de terras, para complementar suas rendas com a produção de carne (11). Por outro lado, procurou-se também acelerar a construção do caminho nôvo que ligaria o Rio de Janeiro às Minas Gerais.

A necessidade de uma vida de comunicações mais rápida entre o Rio de Janeiro e as minas já era preocupação do govêrno desde 1698 . Diligências tinham sido feitas em São Paulo para encontrar alguém que se encarregasse da abertura, mas o único que se oferecera fôra Amador Bueno da Veiga, cujas exigências foram consideradas exorbitantes. Contrataram-se então os serviços de Garcia Rodrigues Pais. O plano do nôvo traçado reduziria o trajeto de três meses para quinze dias e abriria à pecuária a região dos Campos Gerais,

"tão férteis para os gados que dizem êstes homens virão a ser uma nova Buenos Aires" (12).

Aos 7 de setembro de 1702, o governador D. Álvaro da Silveira e Albuquerque, respondia às interpelações régias sôbre o andamento dos trabalhos, dizendo que

"o caminho nôvo não é capaz senão para a gente que vai a pé, carregada com suas cargas, mas não a quem fôr a cavalo, porque não é para isso" (13).

\footnotetext{
(10). - Carta régia de 18 de maio de 1702, Documentos Interessantes, ibidem, pág. 90 .

(11). - Alvará de sesmaria de 18 de abrll de 1701, ibidem, pág. 30.

(12). - Carta de Artur de Sá e Menezes de 24 de maio de 1698, Manuscrito do Arquivo Nacional, Coleçáo Governadores, volume VI, fôlha 142.

(13). - Carta de 7 de agôsto de 1702, Documentos Interesasntes, ibidem, pág. 44.
} 
Garcia Rodrigues lutava contra a falta de auxílio oficial. Várias vêzes as obras foram paralisadas e o contratador retirou-se para o Rio de Janeiro, desanimado com as dificuldades crescentes (14). Finalmente foi-lhe concedido um auxílio em índios em maio de 1704, mas a ajuda financeira foi desaprovada pelo rei, que via nesse financiamento solicitado uma maneira de tornar ainda mais morosos os trabalhos, com a futura repetição de pedidos de socôrro (15). A demora dificultava as operações comerciais. Entre os criadores instalados nas sesmarias recém-distribuidas, vários tentaram atrair a atenção do govêrno para a necessidade de acelerar a abertura da picada. Amador Bueno da Veiga, que via no nôvo caminho uma oportunidade de fazer circular ràpidamente sua produção, voltou a oferecer seus préstimos, comprometendo-se a fazer a ligação entre os campos gerais e o Rio de Janeiro por sua própria conta, já que a rota aberta por Garcia Rodrigues era impraticável para o gado, atravessando durante três meses locais sem mantimentos e segurança (16). A Corôa procurava porém evitar a multiplicação das vias de acesso e, recusando essa e outras ofertas, preferiu aguardar a conclusão dos trabalhos já iniciados (17). Enquanto isso, a rota de São Paulo continuava movimentada e ao longo do percurso progrediam os currais e as roças.

Com a interdição do caminho da Bahia, os criadores paulistas lá estabelecidos aumentaram ainda mais o seu poderio. Sob o pretexto de repressão ao contrabando, seu chefe, Borba Gato; ordenava a apreensão de qualquer combôio que não pudesse provar a sua procedência. $O$ gado confiscado era imediatamente colocado em leilão e os arrematantes eram sempre os paulistas. Acumulavam dessa maneira a produção e a distribuição de carne. $O$ exagêro das confiscações provocaram tantos protestos que em 1704 alguns dos perseguidores tiveram sua autoridade cassada (18). Os prejuízos e as reclamações conseguiram que fôsse liberado o caminho à pecuária em 1705. O tráfico passou a ser legislado pelo regimento dos superintendentes e guarda-mores, de 1702 , que garantia a livre circulação das boiadas, desde que quites com as autoridades fiscais.

Se as perseguições terminaram, o descontentamento continuava. $O$ ódio entre os paulistas e os que êles chamavam pejorativamente de "emboabas" era aumentado pela rivalidade econômica. Para o sertão veio Manuel Nunes Viana, à princípio como mascate, depois estabe-

(14). - Carta de 8 de julho de 1703, ibidem, pág. 186.

(15) . - Carta régia de 13 de março de 1704, ibidem, pág. 230.

(16). - Carta régia de 23 de setembro de 1704, ibidem, pág. 260.

(17). - Carta de Alvaro Baltazar da Sllvelra, de 15 de março de 1705, ibidem, pág. 287.

(18). - Carta de D. Rodrigo da Costa de 8 de julho de 1704, Documentos Históricos, volume XI, Rlo de Janeiro Biblloteca Naclonal, pág. 8. 
lecendo-se com fazendas de criar em Tabua e em Jequitaí. Enriquecido no contrabando, acumulou cabedais que lhe permitiram a ampliação de suas propriedades. O domínio paulista sendo uma limitação às suas ambições, resolveu lutar contra o prestígio dos criadores do vale. Conseguiu convencer D. Isabel, herdeira de Antônio Guedes de Brito, instituí-lo procurador de suas terras e começou a exigir pagamento dos fôros atrasados da antiga propriedade. Suas pretensões não tinham base legal, pois as terras pertenciam tradicionalmente aos primeiros desbravadores, mas a demanda, arrastando-se por longos anos na justiça, trouxe-lhe a admiração de todos os emboabas que ansiavam pelo esfacelamento do domínio paulista. O caso só foi resolvido no govêrno de Antônio de Albuquerque, que proibiu o aforamento, não permitindo a existência de verdadeiros donatários no Brasil (19). Enquanto não conseguia controlar a produção de carne, Manuel Nunes Viana, protegido pelos poderosos comerciantes e criadores da Bahia, obteve o cargo de regente do rio São Francisco e cindiu o poderio paulista trazendo imensas boiadas pelo rio, evitando seus currais, subindo diretamente até Caeté, seu quartel general. Além disso, tentou com seus recursos econômicos, e através de alianças com clérigos, deter o monopólio de distribuição de carne verde, arrematando o estanco dos açougues por meio de associados.

Para garantir a regularidade do abastecimento dos arraiais, o govêrno decidira colocar em leilão os talhos de carne: o contratador tinha a obrigação de assegurar aos açougues os animais necessários no abate semanal e podia arbitrar o preço de venda ao consumidor. De 1701 a 1706, o monopólio de distribuição produziu grandes rendimentos. Os paulistas, vendo escapar-se-lhes para os desafetos essa importante fonte de renda, conseguiram impedir a renovação do contrato pelos emboabas, incitando a população contra a exorbitância dos preços dobrados pelos retalhistas. Essa luta pelo contrôle do fornecimento foi uma das causas da guerra dos emboabas, quando as paixões e os ódios explodiram numa violenta guerra civil. Os desmandos de Borba Gato, expulsando sumàriamente o chefe dos emboabas num prazo de 24 horas, acendeu os ânimos já exaltados e as pequenas agitações iniciais tiveram uma repercussão sangrenta.

A guerra derrubou todo o esquema econômico montado nas Minas Gerais. Os paulistas foram afastados dos cargos públicos e a administração passou a ser exercida exclusivamente pelos reinóis. 0 contrabando foi reprimido pela cobrança dos direitos de passagem. A distribuição e o comércio de carne eram agora atribuições das câmaras municipais. Os paulistas retrairam-se com os insucessos da

(19). - Carta do Conde de Assumar de 10 de outubro de 1718, Revista do Arquivo Público Mineiro, ano XXIII, Belo Horizonte, 1929, pág. 222. 
luta e os marchantes passaram a dominar a pecuária, negociando diretamente com as autoridades o abastecimento dos açougues. Esses intermediários, servindo de elemento de ligação entre os criadores e os consumidores, atiraram-se à especulação com os preços e transformaram-se numa classe poderosa e odiada. Com o contrôle da rêde de talhos, impunham à população e aos criadores as suas condições; desafiando a própria lei com suas exorbitâncias .

Cabia às câmaras municipais a fixação dos preços de carne verde, mas os vereadores eram manejados pelo poder econômico dos marchantes e cumpriam exclusivamente suas ordens. Os preços eram assim irregularmente arbitrados, e variavam de local a local, de acôrdo com a retração ou a expansão do mercado. O recurso dos criadores era desviar suas boiadas para aquêles arrraiais que oferecessem maiores vantagens, e o abastecimento tornou-se mais uma vez precário. Em Vila Rica, por exemplo, a câmara viu-se em apuros para estabilizar o fornecimento à população: convocaram-se os

\footnotetext{
"credores e mais pessoas tratantes em gados e a todos os homens bons e povos da villa para efeito de se assentar a melhor forma em que se hão de estabelecer os talhos, sem que os povos e criadores de gado recebam prejuízo" (20).
}

Na reunião, realizada no dia 18 de janeiro de 1712 , a câmara concordou em trocar suas prerrogativas e regalias por um imposto de

\footnotetext{
"meia pataca em cada cabeça de gado, que nesta vila a seu têrmo se cortar, não excetuando desta contribuição mais que os credores e pessoas que tratar em gado" (21).
}

Esses "credores" e mais pessoas tratantes em gados constituiam a maioria dos presentes, que conseguiram impor suas condições. $\mathrm{O}$ impôsto, se teòricamente recaía sôbre todos os criadores de gado, não atingia aos marchantes, que utilizaram a impunidade fiscal para aumentar seu jugo sôbre os fazendeiros. Estes reagiram contra a injustiça da decisão e boicotaram a vila, procurando outras regiões onde o impôsto fôsse igualitário e menos extorsivo. O primeiro arrematante desistiu do contrato dois meses antes de seu término, desencorajado pela dificuldade de atrair rebanhos para os currais vazios e abandonados (22). Em 1713, ninguém se apresentou como candidato ao duvidoso lucro. Como represália, os marchantes conseguiram convencer a câmara a decretar que

\footnotetext{
(20). - Ata de 7 de janeiro de 1712, "Atas da Câmara Munlcipal de vila Rlca", Anais da Biblioteca Nacional, volume XLIX, Rio de Janeiro, Ministério da Educação, 1936, pág. 219.

(21). - Ata de 18 de janeiro de 1712, ibidem, pág. 221.

(22). - Ata de 29 de outubro de 1712, ibidem, pág. 250.
} 


\begin{abstract}
"nenhuma pessoa pudesse comprar boi algum em pé no curral com pena do perdimento do mesmo boi e de trinta dias de cadeia" (23).
\end{abstract}

As estradas de Vila Rica foram fechadas com cancelas nas pontes, para obrigar os criadores locais a vender no próprio têrmo. Os resultados foram nulos: o abastecimento só foi normalizado quando o impôsto de meia pataca foi trocado pelo preço máximo de 1 oitava por 20 libras de carne (24). Conseguindo assim transferir o pagamento da taxação aos marchantes, os criadores suspenderam a greve e os açougues começaram a receber animais duas vêzes por semana, aos sábados e têrça-feiras, sob contrôle municipal. Os comerciantes foram intimados a respeitar os preços estipulados. A vitória em Vila Rica entusiasmou os fazendeiros de todo o território e em breve a medida foi ampliada, e as outras câmaras que ainda exploravam diretamente o comércio de gado cancelaram o privilégio por ordens governamentais.

Essa vitória dos pecuaristas não abalou porém o poder dos marchantes. Senhores de uma vasta rêde de açougues, aceitaram a fiscalização do govêrno na cobrança dos preços máximos de venda, mas mantinham ampla liberdade de impor seus preços de compra. Os criadores, impedidos legalmente de vender seus rebanhos diretamente ao consumidor, tiveram que se resignar às suas imposições. A mercadoria chegava cara aos fregueses dos açougues, mas os lucros eram altamente proveitosos aos intermediários. Ante a impossibilidade de enfrentar os poderosos donos do comércio de carne, os criadores retiraram-se para suas fazendas, procurando compensar com o aumento dos rebanhos a diminuição dos lucros. Para isso, fixaram-se nas propriedades, para melhor administração de seus interêsses. A pecuária, de atividade rural, transformou-se em atividade urbana. Se antes o campo impunha suas condições às vilas, agora era o inverso: a. consolidação do povoamento urbano tornou o campo dependente, e das vilas é que vinham as̃ diretrizes econômicas para o sertão.

Quando a capitania de Minas Gerais foi instalada, em 1720, a pecuária já atravessara todo um ciclo evolutivo e se cristalizara como atividade básica da região. Os primeiros criadores, fugitivos da asfixia comercial imposta pelos comerciantes baianos, e que haviam implantado na zona da mineração um verdadeiro império econômico, tinham sido esmagados pela investida dos marchantes. A Corôa, enquanto precisou da colaboração dos antigos guerreiros - então sedentarizados - para assegurar a pacificação e o abastecimento,

(23) . - Ata de 1 de abril de 1713, ibidem, pág. 266.

(24). - Ata de 26 de fevereiro de 1715, ibidem, pág. 366. 
apoiou-os contra o adventícios e deu-lhes o poder político. Assim que a ocupação das gerais tornou-se estável e a produção do ouro suficiente para alimentar os cofres régios, o govêrno aliou-se ao comércio para combater o prestígio dos caudilhos. O mercantilismo português, que via na criação de vilas e na fixação urbana do povoamento uma maneira de fortalecer o metalismo, através, da cobrança de impostos e taxas, não podia continuar a aceitar os antigos aliados que enfraqueciam seus fundamentos. Confinados em longínquos municípios isolados, transformados em "homens bons" de câmaras inexpressivas, os pecuaristas vão assistir a derrrocada de seu poder econômico e de seu prestígio político, transferidos para os comerciantes e burocratas. De dirigentes dos destinos do nôvo território, passaram a chefes regionais, com área de influência limitada pelas cêrcas de suas propriedades. Afastados dos acontecimentos políticos da colônia, num ostracismo constrangedor, só se movimentarão, débil e esporàdicamente, nos pequenos motins inconsequientes acontecidos no início da existência da capitania. Estarão ausentes dos movimentos separatistas e só reassumirão uma liderança após a abdicação, quando a criação da Guarda Nacional e a reforma do Código do Processo Criminal revigoraram o municipalismo e fortaleceram a classe rural. Durante todo o período colonial continuaram controlados pelos marchantes que, organizados em escala capitalista, dirigiam de Vila Rica um intenso tráfico de gado do Rio de Janeiro, São Paulo, Bahia, e de outros pontos distantes da colônia, numa integração completa de todo o rebanho nacional. 